\begin{tabular}{|l|l|l|l|l|l|l|}
\hline InterteXto & Uberaba & UFTM & v. 4 & p. 52-65 & 2011 - jan. / jul. & ISSN 1981-0601 \\
& & & n. 1 & & & \\
\hline
\end{tabular}

\title{
REVISTA DE UBERABA: UM ESBOÇO HISTÓRICO
}

\section{REVISTA DE UBERABA: AN OUTLINE HISTORY}

Taís Iniz de Paiva ${ }^{1}$

Ozíris Borges Filho ${ }^{2}$

RESUMO: O presente artigo pretende divulgar os resultados de uma pesquisa de iniciação científica realizada durante o ano de 2010 sobre o periódico intitulado Revista de Uberaba. Este periódico circulou entre os anos de 1904 e 1905 na cidade de Uberaba sob a editoria de Felício Buarque, promotor da comarca da cidade na época, juntamente com o proprietário e chefe da livraria e tipografia Século XX. Arédio de Souza.

PALAVRAS-CHAVE: periódico; Revista de Uberaba; digitalização; História da Literatura.

ABSTRACT: This article aims to show the results of a scientific initiation research conducted during 2010 on the journal titled Revista de Uberaba. This journal circulated between the years 1904 and 1905 under the editorship of Felicio Buarque KEYWORDS: Journal; Revista de Uberaba; scanning; History of Literature.

\section{INTRODUÇÃO}

A cidade de Uberaba possui uma grande produção literária e escritores renomados, porém já esquecidos. O interesse de realizar a pesquisa surgiu dada a importância de se resgatar essa literatura para melhor conhecer e entender o cidadão uberabense, bem como construir e divulgar a história literária da cidade.

Como nosso principal objetivo era resgatar essa história, realizamos entrevistas com historiadores e intelectuais do município à procura de informações relacionadas à época do surgimento da revista e também informações sobre como o periódico foi recebido na cidade, qual era o seu

\footnotetext{
${ }^{1}$ Aluna do $7^{\circ}$ período curso de Letras da Universidade Federal do triângulo Mineiro - UFTM- UberabaMG. Bolsista PET. E-mail: taisinhapaiva@yahoo.com.br

${ }^{2}$ Professor Dr. Adjunto III da Universidade Federal do Triângulo Mineiro - UFTM- Uberaba-MG. Bolsista PET. E-mail: oziris@,oziris.pro.br
} 


\begin{tabular}{|l|l|l|l|l|l|l|}
\hline InterteXto & Uberaba & UFTM & v. 4 & p. 52-65 & 2011 - jan. / jul. & ISSN 1981-0601 \\
& & & n. 1 & & & \\
\hline
\end{tabular}

público, sua tiragem, etc. Essas informações foram gravadas e transcritas posteriormente na tentativa de reconstruir a historicidade do periódico.

As edições encontradas da revista estavam em péssimo estado, por serem edições originais do século passado. O papel estava bem amarelado, gasto. Por não estarem guardadas em local apropriado e por não receberem o cuidado devido, muitas folhas já não estavam inteiras. Por isso, o periódico foi minuciosamente remontado e digitalizado para que, dessa forma, esse patrimônio cultural uberabense fosse preservado e servisse de material para futuros pesquisadores. Após digitalizar todas as edições da Revista de Uberaba, um CD com todo esse material foi gravado, copiado, sendo uma das cópias doada ao Arquivo Público da cidade e outras a alguns historiadores que contribuíram para a pesquisa, garantindo assim, o acesso de todos às revistas. Em seguida, foram realizadas algumas análises literárias dos textos poéticos dos autores uberabenses, contidos na revista.

\section{A REVISTA}

O periódico Revista de Uberaba foi criado em 1904, editado e dirigido por Felício Buarque, promotor da comarca da cidade na época, em parceria com o proprietário e chefe de uma das primeiras livraria e tipografia da cidade, chamada Século XX, de propriedade de Arédio de Souza.

O primeiro fascículo da revista entrou em circulação em março de 1904, sendo publicado um a cada mês, no período de um ano, sendo o último exemplar publicado em fevereiro de 1905. Cada edição da revista continha em média trinta páginas, salvo a última edição, de fevereiro de 1905, que contou com oitenta e cinco páginas, recheadas de artigos de escritores conhecidos e amigos de Felício Buarque, além de intelectuais que colaboraram com a revista, parabenizando o editor pelo sucesso da mesma. Nessa edição final, também há um longo histórico feito pelo próprio editor sobre os doze meses de edição da revista, em um artigo intitulado: Através de um anno, no qual ele 


\begin{tabular}{|l|l|l|l|l|l|l|}
\hline InterteXto & Uberaba & UFTM & v. 4 & p. 52-65 & 2011 - jan. / jul. & ISSN 1981-0601 \\
& & & n. 1 & & & \\
\hline
\end{tabular}

descreve como foi o andamento da Revista de Uberaba durante o período de sua publicação e faz todos os esclarecimentos e agradecimentos necessários.

Algumas das edições da Revista de Uberaba encontradas eram em capa dura com o mesmo design gráfico, variando apenas as cores das capas: verde, azul e vermelha, as outras edições estavam em capa dura também, porém foram encadernadas juntas, pois, segundo os relatos dos historiadores entrevistados, suas capas já haviam se perdido. Todas as edições tinham suas páginas numeradas em algarismos arábicos e a numeração era contínua de uma edição para a outra, ou seja, a numeração era seqüencial. Por exemplo, na primeira edição temos a numeração da página três até a página vinte e cinco e na segunda edição temos a sua continuação. A primeira página da revista se inicia em vinte e seis e vai até a página cinqüenta e um e assim sucessivamente até a última edição, que termina na página trezentos e quarenta e cinco, na décima segunda edição.

A Revista de Uberaba não teve grande circulação, seu público era restrito, pois esta era uma revista de intelectuais, políticos, poetas e escritores. Naquela época, saber ler era para poucos, apenas as pessoas mais ricas possuíam tal conhecimento ou então pagavam alguém para a leitura e por isso o periódico não sobreviveu por muito tempo. Soma-se a isso também, a questão da falta de verba para financiá-la. Por isso, o periódico encerrou sua circulação após um ano de sua estréia.

Segundo historiadores entrevistados, acredita-se que a tiragem da revista girava em torno de duzentos a trezentos exemplares por mês, ainda assim um número pequeno diante dos gastos para mantê-la.

A revista procurava agradar a todos os gostos. Além de um grande espaço dedicado à literatura, havia também levantamentos de dados sobre a cidade de Uberaba e região. Os autores abordavam fatos cotidianos do município, explicitavam suas opiniões políticas, escreviam sobre religião, agricultura, industrialização, cultura geral, faziam homenagens a pessoas importantes da cidade, que contribuíram com o periódico, etc. Era uma revista 


\begin{tabular}{|l|l|l|l|l|l|l|}
\hline InterteXto & Uberaba & UFTM & v. 4 & p. 52-65 & 2011 - jan. / jul. & ISSN 1981-0601 \\
& & & n. 1 & & & \\
\hline
\end{tabular}

informativa e também de entretenimento, chamada por seus criadores de Orgão litterário, scientifico e industrial.

A sua edição se deu pela livraria e tipografia Século $X X$ de propriedade de Aredio de Souza. Essa era a única tipografia da cidade naquele tempo e, portanto, editava também outros jornais e periódicos em circulação no município, como por exemplo, o Almanaque Uberabense, que surgiu antes da Revista de Uberaba. Segundo informações da historiadora Eliane Marquez, Aredio de Souza, que era seu tio avô, foi um homem muito influente em Uberaba e com uma visão de mundo além do seu tempo. Foi um dos pioneiros a criar uma gráfica, e esta foi uma grande empresa dentro do município. A gráfica progrediu muito, editou outras revistas e jornais da cidade, além da Revista de Uberaba, mas fechou as portas após um tempo. A historiadora não soube informar ao certo o motivo do fechamento da gráfica, nem a data precisa, mas suspeita-se que pode ter sido também pela falta de recursos financeiros. Eliane relatou que a livraria se situava na rua chamada hoje de Artur Machado, numa construção antiga, onde hoje funciona o Bar e Choperia do Mário em Uberaba.

Analisando a Revista de Uberaba, logo se nota a semelhança com o Almanaque Uberabense, outro periódico em circulação da época. Nos dois periódicos, tem-se o mesmo estilo, a mesma estética, o que leva a acreditar que a revista surgiu da mesma forma e no mesmo ritmo dos outros periódicos da mesma data, um grupo de intelectuais com vontade e ânsia de se expressar e divulgar a todos seus pensamentos, ou seja, intelectuais à procura de um espaço para a concretização e divulgação de suas obras e estudos.

O periódico é dividido em seções com diversos artigos. Em todas as edições da revista, a literatura se faz presente em seu começo, geralmente as cinco primeiras páginas das edições eram reservadas a textos literários diversos como os contos e principalmente os textos em forma de poema. Neste espaço existem muitos textos românticos, tendência da época, ilustrados com gravuras Art Nouveau, estilo comum no momento. Essas gravuras davam vida 


\begin{tabular}{|l|l|l|l|l|l|l|}
\hline InterteXto & Uberaba & UFTM & v. 4 & p. 52-65 & 2011 - jan. / jul. & ISSN 1981-0601 \\
& & & n. 1 & & & \\
\hline
\end{tabular}

à revista, deixavam-na mais atraente e atrativa.

Há também, nas páginas finais de cada edição da revista, a Chronica Mensal, relatos detalhados sobre os acontecimentos marcantes na cidade, durante o respectivo mês, assinadas com o pseudônimo Athas. O uso de pseudônimos era muito comum nesta época. Em sua crônica, Athas explicitava fatos importantes da cidade, como por exemplo, a chegada de pessoas ilustres, o comportamento de pessoas conhecidas ou a indelicadeza de terceiros, estréia de musicais, teatro, enfim, coisas corriqueiras que, para aquela população, chamava a atenção. Seu relato era minucioso e recheado de comentários irônicos que, com certeza, era um prato cheio aos fofoqueiros de plantão.

Por mais que a ideia do surgimento da revista tenha sido inicialmente a de ser um espaço para intelectuais se expressarem, ela também se preocupou com determinados assuntos importantes para o leitor uberabense. Exemplos disso são os textos jurídicos, escritos pelo próprio editor, relatando a criminalidade na cidade e em cidades vizinhas. Há um espaço em que Felício faz um estudo dos crimes ocorridos, dos julgamentos, das prisões e absolvições, do funcionamento das leis penais no município e na região, enfim, ele faz um paralelo entre a criminalidade em Uberaba e outras cidades vizinhas para exigir melhorias no sistema penal do município. Através desses ensaios se percebe a preocupação do promotor da comarca uberabense com a segurança de seu povo. Esse estudo foi feito mensalmente e publicado em todas as edições da revista em forma de artigo intitulado: $A$ criminalidade em Uberaba - Ensaio de criminologia local.

Além dos casos jurídicos, encontram-se estudos agrícolas, sobre o solo, plantações e até mesmo observações sobre a meteorologia, para indicar o momento certo de plantar e colher, que tipo de semente é propícia para a época, etc. O que na verdade é muito interessante e pertinente. Já que Uberaba é a terra do gado zebu, povoada por fazendeiros, nada mais democrático que voltar um pouco a atenção da revista para este tipo de 


\begin{tabular}{|l|l|l|l|l|l|l|}
\hline InterteXto & Uberaba & UFTM & v. 4 & p. 52-65 & 2011 - jan. / jul. & ISSN 1981-0601 \\
& & & n. 1 & & & \\
\hline
\end{tabular}

público. Esse estudo também se desenvolve em discussões sobre a evolução das indústrias da época e proporciona aos seus respectivos leitores, uma reflexão acerca do assunto. Daí o devido ensaio ser intitulado como: O futuro Industrial de Minas Gerais e ter sua publicação mensalmente em todas as edições da revista, assim como os artigos sobre criminalidade.

A revista contava ainda com textos de escritores de fora ou convidados por Felício que completavam a edição com muito bom gosto. Estes textos iam desde biografias de pessoas importantes do município, até cartas de agradecimento e enaltecimento ao editor da revista.

Ressalta-se também o espaço separado, ao final de cada edição, para agradecimentos do editor aos colaboradores da revista, notas sobre o recebimento de trabalhos, divulgação de outras revistas, elogios a jornais e outros editores, etc. Este espaço era intitulado: Notas e Recados, e nele também havia cobranças aos leitores devedores. Sim, havia páginas destinadas a cobrar, literalmente, as pessoas que adquiriam o periódico, mas que ainda não tinham efetuado o pagamento do mesmo. Sendo assim, Felício encontrou um jeito de comunicar aos devedores, às vezes de forma bem irônica, que a falência da revista estava aproximando devido a clientes inadimplentes. Trata-se de uma estratégia inédita até então no município e muito ousada da parte do editor, a qual, no final, acabou não dando certo, pois os clientes acabaram parando de comprar o periódico e não acertaram o saldo devedor, e a revista veio, de fato, a encerrar sua circulação: 


\begin{tabular}{|l|l|l|l|l|l|l|}
\hline InterteXto & Uberaba & UFTM & v. 4 & p. 52-65 & 2011 - jan. / jul. & ISSN 1981-0601 \\
& & & n. 1 & & & \\
\hline
\end{tabular}

Aos nossos assignantes

Aos nossos dignos assignantes rogamos o especial obsequio de satisfazerem o pagamento de suas assignaturas, para que não tenhamos grandes prejuisos materiaes, embora com a abstracção da perda de tempo e de trabalho.

Chamando-lhes a atenção para o nosso artigo Através de um anno, esperamos bem merecer-Ihes tão especial obsequio.

A Redacção.

(REVISTA DE UBERABA, 1905, p.344)

A revista contava ainda, nas páginas finais de cada edição, com propagandas publicitárias de empresas do município. Estas empresas contribuíam financeiramente para a revista e, em troca, Felício estampava as páginas finais com os seus respectivos anúncios de produtos e serviços. Os tipos de anúncios eram os mais diversos possíveis, desde fórmulas miraculosas de remédios caseiros, restauradores de cabelos para pessoas calvas, compra e venda de grãos como café e arroz, até venda de máquinas agrícolas, cimento, ferro, charutos, etc. Além das empresas, há também os anúncios da tipografia Século $X X$ de Arédio, vendendo seus serviços de encadernação, pautação, etc. e também os de Felício, como advogado e consultor.

As propagandas tinham o nome da empresa ou produto em destaque, um pequeno texto logo abaixo, sucinto sobre o produto ou serviço, que nem por isso deixava de ser pretensioso. Em algumas há até promessa de cura total de enfermidades, sendo bastante apelativas como as dos dias atuais, mas talvez um tanto mais cômicas por tamanha ousadia. Grande parte dos anúncios estampava metade de uma página, mas há algumas empresas com destaque maior, tendo exclusividade de uma página inteira. A maioria da publicidade era decorada com desenhos dos produtos ou logos da marca do produto e da empresa, para deixar o anúncio mais atrativo para o público.

Alguns dos escritores presentes na revista eram pessoas importantes de 


\begin{tabular}{|l|l|l|l|l|l|l|}
\hline InterteXto & Uberaba & UFTM & v. 4 & p. 52-65 & 2011 - jan. / jul. & ISSN 1981-0601 \\
& & & n. 1 & & & \\
\hline
\end{tabular}

Uberaba, ou que vieram para a cidade e contribuíram muito com a mesma, por exemplo, o próprio Felício Buarque, Borges Sampaio, Militino Pinto, etc. Os outros escritores presentes no periódico são de cidades vizinhas a Uberaba, e alguns são de fora, não sendo possível identificar muitos desses escritores, pois o uso de pseudônimos era comum na época. São eles: Silvestre de Lima (Barretos); Pelayo Serrano (Espanha); Nelson de Senna (Serro); Mendes de Oliveira; Celso Werneck (Belo Horizonte); Antônio Borges Sampaio; Felício Buarque (Recife); Militino Pinto (Uberaba); Belmiro Braga (Juiz de Fora); Mário de Lima (Belo Horizonte); A. Pinheiro Campos (São João Del Rey); Polybyus (Monte Alegre); P.X; Athanásio Saltão; Eduardo Cerqueira (Belo Horizonte); Deoclecyano Marthyr (Brasília); Rodrigues da Cunha (Belo Horizonte); Evaristo Gurgel; Jaynor (Ouro Preto); Estevam Leão Bourroul (São Paulo); Tomás O’Connor D’Arlach (Bolívia); Euclides Bandeira (Curitiba); Gama e Silva (Rio de Janeiro); Gomes de carvalho (Belo Horizonte); Belarmino Carneiro (Recife); C. Brunetto (Rio de Janeiro); Álvaro Vianna; Alphonsus de Guimaraens (Ouro Preto); Oliveira Castro; Auta de Souza (Rio Grande do Norte); Borges Sampaio (Portugal); Luciano Gualberto; A. S. Castro Menezes; Castro Magalhães; Julia Lopes D’Almeida (Rio de Janeiro); Elydio de Andrade; Paulo Brandão; José Maria dos Reis; Dr. Pedro Sanches de lemes (Poços de Caldas); D. Batalha; Carlos Velloso (Vila Rica); Maria Dolabella; Ricardo Paranhos (Catalão); Q. Jardim Junior; Absay de Andrade (Catalão); Augusto Franco (Belo Horizonte); Licino (Barretos).

Cada um desses escritores deixou sua marca na Revista de Uberaba, muitos até ficaram conhecidos através desta. Os textos tratavam sobre diversos assuntos e eram bons textos, poesia de boa qualidade, uma poesia independente, social, carregada de expressões particulares. Dentre os vários poetas contidos na revista, sem dúvida, Felício teve notório destaque. Além dos extraordinários ensaios sobre criminalidade, ele também participou do periódico com as suas próprias poesias. Em uma análise mais profunda de seus textos, é possível conhecer melhor esse homem que, apesar de não ser uberabense de 


\begin{tabular}{|l|l|l|l|l|l|l|}
\hline InterteXto & Uberaba & UFTM & v. 4 & p. 52-65 & 2011 - jan. / jul. & ISSN 1981-0601 \\
& & & n. 1 & & & \\
\hline
\end{tabular}

nascimento, adotou Uberaba como sua cidade e fez muito por ela.

\section{JOSÉ FELÍCIO BUARQUE DE MACEDO}

Nasceu dia $1^{\circ}$ de novembro de 1865 , na cidade de Maragogy no estado das Alagoas, filho de José Felício Buarque e Germana Maria das Neves. Nessa cidade fez o curso de primeiras letras, seguindo depois para o Recife, onde se matriculou no colégio das Artes e começou a estudar preparatórios. Depois de terminado, matriculou-se na academia de Direito da capital de Recife, finalizando seu curso em 29 de maio de 1894, tornando-se bacharel em direito.

Sua vida sempre foi muito difícil. Nascido de uma família pobre, seus pais não tinham recursos, ele recebeu ajuda então, de uma madrinha que residia em Pernambuco e que custeou seus estudos. Antes mesmos de terminar os preparatórios ele já dava aulas para o curso primário e algumas matérias do secundário para ter dinheiro suficiente para sua matrícula na faculdade, comprar livros e se manter.

Nesse tempo ele já fora seduzido pela imprensa pernambucana e aos poucos foi se envolvendo, chegando a fundar e dirigir periódicos. Toma assim gosto pela política, tornando-se um combatente das idéias democráticas. Felício fundou ali um órgão literário e republicano chamado O Século, de 1883 a 1884.

Em 1889 proclamou-se a República, Felício exercia o cargo de $1^{\circ}$ secretário do club Republicano Frei Caneca, era também correspondente da república Brasileira que se publicava no Rio de Janeiro sob a direção de José Candido Teixeira. No ano seguinte, Felício fundou no Recife o club Republicano do Recife, sendo eleito seu presidente. Concorreu ainda em 1891, para a fundação União Cívica de Pernambuco, importante agremiação partidária, de cuja diretoria fez parte, publicando vários manifestos sobre a política do Estado.

Em oito de maio de 1890, foi nomeado para o cargo de amanuense da repartição da Instrução Pública de Pernambuco, no qual se manteve até 10 de 


\begin{tabular}{|l|l|l|l|l|l|l|}
\hline InterteXto & Uberaba & UFTM & v. 4 & p. 52-65 & 2011 - jan. / jul. & ISSN 1981-0601 \\
& & & n. 1 & & & \\
\hline
\end{tabular}

outubro do mesmo ano, pois foi exonerado do seu cargo, em vista da oposição feita no jornal A Epocha ao governo de então do Senhor Barão de Lucena. Em quatro de janeiro de 1892, após deposição do governo, foi reintegrado no mesmo cargo pela Junta Governativa que então dirigia o governo do Estado.

Durante seu afastamento esteve como revisor do Jornal do Recife, de que também era redator. Nessa época cogitava em seu estado natal a eleição para renovação do mandato do cargo de Governador. A esse fim Felício dedicou sua atividade já fundando o Centro Alagoano e dirigindo manifesto ao Congresso do Estado.

Com a ascensão do major Gabino Besouro ao governo das Alagoas, Felício Buarque foi nomeado Secretário do Interior. Mas permaneceu nesse cargo só até 18 de maio de 1893. Insistiu por sua exoneração, alegando divergências de princípios. Voltou então para o teatro de suas primitivas lutas, para Recife, sendo nomeado para o cargo de secretário da comissão do Lazareto em $1^{\circ}$ de novembro de 1893 , em que era chefe o coronel Antônio Geraldo de Souza Aguiar.

Em 1894, Felício publicou As Origens republicanas, demonstrando todas as suas idéias sobre a questão republicana e sua paixão pelas instituições democráticas. Felício chegou até a alistar-se por causa da revolta de seis de setembro, mas o governo não aceitou seu alistamento, agradecendo sua atitude, mas alegando que não era necessário devido ao excesso de contingentes. Felício então julgou restrito o campo para suas operações e partiu para o Rio de Janeiro em outubro de 1894, onde se manteve até março do ano seguinte. Foi nomeado então promotor da justiça da comarca de Ayuroca pelo governo Bias Fortes.

Agora, num cenário um pouco diferente do qual estava acostumado, Felício continua com o mesmo espírito de evolução, o mesmo combatente, o mesmo escritor, o mesmo jornalista, pregando as mesmas doutrinas, superando as dificuldades. O tempo, o espaço e o meio não o deturparam. No cargo de promotor Público, manteve-se desde março de 1895 até o mesmo 


\begin{tabular}{|l|l|l|l|l|l|l|}
\hline InterteXto & Uberaba & UFTM & v. 4 & p. 52-65 & 2011 - jan. / jul. & ISSN 1981-0601 \\
& & & n. 1 & & & \\
\hline
\end{tabular}

mês do ano de 1898.

Em 30 de abril de 1896 se casou em Ayuruoca com Thereza Buarque, que desde então fora sua companheira em suas lutas e trajetória.

Então Felício, sob influência de sua esposa, deixou o cargo de promotor, alegando que seu temperamento, sua educação cívica e seus princípios políticos não se relacionavam com o mandonismo local. Foi removido então para a comarca de Dores da Boa Esperança onde passou a advogar e, desapegado da função pública que o inibia das lutas partidárias de preferir este ou aquele grupo.

Em 24 de setembro de 1900, foi nomeado promotor de justiça da comarca de Uberaba, assumindo o exercício desde três de novembro de 1900 a três de novembro de 1904. E também presidiu o Grêmio Bernardo Guimarães.

\section{A POESIA DE FELÍCIO}

Durante as análises dos textos literários de Felício Buarque na Revista de Uberaba, notam-se algumas semelhanças e diferenças entre eles. Foi realizada uma análise de cinco textos do autor, encontrados nas revistas. Procedendo assim, a busca se deu por conhecer melhor o autor uberabense e entender como era a literatura dessa época, já que a revista foi lançada em 1904, século XX, para então conhecer um pouco mais sobre como a literatura circulou na cidade.

Percebe-se que o autor tinha uma preocupação em escrever sobre os problemas do mundo e da sociedade em sua volta. Em seus textos, nota-se uma visão generalizada dos problemas e conflitos que o rodeiam e não somente problemas intimistas, pessoais e particulares. Existem nos poemas algumas temáticas sociais como, por exemplo, a questão da implantação da república no Brasil, que foi um marco importante para o país que, sem dúvida, atingiu a todos os brasileiros. O poeta mostra o seu olhar sobre tal fato histórico 


\begin{tabular}{|l|l|l|l|l|l|l|}
\hline InterteXto & Uberaba & UFTM & v. 4 & p. 52-65 & 2011 - jan. / jul. & ISSN 1981-0601 \\
& & & n. 1 & & & \\
\hline
\end{tabular}

em um de seus poemas.

Outra característica que se pode notar também segundo as análises, é a questão religiosa presente em vários poemas de Felício. O autor sempre faz uma menção às questões espirituais. Como exemplo disso tem-se o poema intitulado: O Festim de Macheronte, no qual Felício cria seu poema a partir de uma passagem bíblica. Assim fica notável que a questão da fé, da religião é algo bem marcante em sua poesia e acaba sendo um indício de autoria do poeta.

Outro ponto comum nos poemas de Felício Buarque é a linguagem utilizada. Seus poemas são todos escritos em linguagem culta, com um vocabulário rico e sempre dentro das regras clássicas da metrificação. Essa escolha pode ser entendida devido à época em que o poeta escreveu seus poemas, mas sem dúvida faz parte do seu estilo de composição.

Outro fato que também chama atenção nos poemas é que a maioria é dedicada a pessoas queridas e amigas dele. O que torna o poema um tanto mais intimista e pessoal, pois o leitor que lê seu poema e vê que este é dedicado a alguém, no mesmo instante já imagina o grau de amizade existente entre eles e também a pessoa a quem ele se destina. Enfim, dá um toque muito pessoal e interessante ao poema.

Sobre as diferenças, o que se destaca nos poemas, é que mesmo ele sendo um poeta preocupado com questões sociais e temas universais, ele também é um poeta muito observador e sentimental, pois também fala sobre emoções e coisas simples da vida que nos cerca. O que dá um toque especial às suas obras é o fato de que não falam sempre de um mesmo tema, cada poema fala de algo distinto. O poeta não insiste em um só lugar comum para criar sua poesia, tornando-a assim bem diversa e acessível a qualquer pessoa, pois não contempla somente um tipo de leitor. Pode-se dizer então que Felício é um poeta completo, que trata de sentimentos, de questões sociais, de religião, enfim, aborda vários assuntos sem perder a sua originalidade e a sua marca. 


\begin{tabular}{|l|l|l|l|l|l|l|}
\hline InterteXto & Uberaba & UFTM & v. 4 & p. 52-65 & 2011 - jan. / jul. & ISSN 1981-0601 \\
& & & n. 1 & & & \\
\hline
\end{tabular}

Assim como outros poetas presentes na Revista de Uberaba, Felício se preocupava em atender a todo tipo de público e a cumprir o lema da revista: que era o de ser uma revista de cunho informativo, industrial, científico e de entretenimento. Dessa forma, descobre-se que a poesia em Uberaba era uma poesia bastante rica e interessante, que não se focava em um só tipo e estilo de poesia. Embora não tendo o periódico sobrevivido por muito tempo, sem dúvida foi um marco na história literária da cidade de Uberaba.

\section{CONSIDERAÇÕES FINAIS}

Com essa pesquisa, conclui-se que a história literária de uma cidade é um patrimônio que deve ser resgatado e respeitado.

A partir deste estudo, foi possível conhecer um pouco sobre o perfil dos poetas uberabenses que iniciaram a carreira literária aqui e, sem dúvida, conhecer melhor também os cidadãos da cidade no século passado. É uma maneira de reviver a história e conhecer as suas raízes, para entender melhor o passado cultural do município.

O resgate dessa revista, bem como sua digitalização, foi uma forma de manter vivo o início da literatura em Uberaba, para passar a futuras gerações um pouco de toda essa história e conhecimento. Foi uma pesquisa para nós bastante importante e que possibilitou a oportunidade de conhecer e aprender um pouco mais sobre os conflitos existentes na época vistos pelos olhos de um poeta da cidade.

Acredita-se que essa pesquisa além de proporcionar um crescimento intelectual e cultural muito grande, também contribuiu para um amadurecimento profissional, pois ao trabalho de pesquisador foi associado o de historiador. Enfim, acredita-se ter contribuído um pouco para a cidade, para a história literária uberabense e para futuros cidadãos e estudiosos da área.

\section{FONTES CONSULTADAS}




\begin{tabular}{|l|l|l|l|l|l|l|}
\hline InterteXto & Uberaba & UFTM & v. 4 & p. 52-65 & 2011 - jan. / jul. & ISSN 1981-0601 \\
& & & n. 1 & & & \\
\hline
\end{tabular}

AUERBACH, Erich. Introdução aos estudos literários. São Paulo: Cultrix, 1972.

BARTHES, Roland. Rumor da língua. São Paulo: Brasiliense, 1987.

BENJAMIN, Walter. Sobre o conceito de história. In: Obras escolhidas. São Paulo: Brasiliense, 1985.

LIMA, Luiz Costa. Teoria da Literatura em suas fontes. $2^{\circ}$ v. Rio de Janeiro: Francisco Alves, 1984.

ZILBERMAN, Regina. Estética da recepção e história da literatura. São Paulo: Ática, 1999. 